\title{
TECNOLOGÍAS DE INFORMACIÓN Y COMUNICACIÓN PARA EL TURISMO INCLUSIVO*
}

\author{
DIANA CRISTINA RODRÍGUEZ MORENO** \\ UNIVERSIDAD PEDAGÓGICA Y TECNOLÓGICA DE COLOMBIA
}

Recibido/ Received/ Recebido: 14/07/2016 - Aceptado/ Accepted/Aprovado: 30/09/2016

\begin{abstract}
Resumen
El propósito de este trabajo es presentar las tecnologías de información y comunicación que tienen potencial para permitir la inclusión de personas con discapacidad como clientes de los destinos turísticos. Las tecnologías fueron identificadas a través de la búsqueda de información en bases de datos académicas y páginas web de empresas proveedoras de tecnologías de información para personas en estado de discapacidad, indicando cómo pueden ser usadas en las actividades de la cadena de valor turística. Se encontró que las tecnologías usadas en los campos de entretenimiento, educación, salud y artefactos diseñados para facilitar la vida de personas con discapacidad, pueden ser utilizados en la industria turística, asistiéndolos en funciones mentales, sensoriales, de voz y habla, neuromusculoesqueléticas y de movimiento.
\end{abstract}

Palabras clave: TIC; Turismo inclusivo; Discapacidad; Cadena de valor turística.

\section{INFORMATION AND COMMUNICATION TECHNOLOGIES FOR INCLUSIVE TOURISM}

\begin{abstract}
The purpose of this work is to present the information and communication technologies that have the potential to allow the inclusion of people with disabilities as clients of tourist destinations. The technologies were identified through the search of information in academic databases and web pages of companies providing information technology for people in a state of disability, indicating how they can be used in the activities of the tourism value chain. It was found that the technologies used in the fields of entertainment, education, health and artifacts designed to facilitate the lives of people with disabilities, can be used in the tourism industry, assisting them in mental, sensory, voice and speech, neuromusculoskeletal and movement functions.
\end{abstract}

Keywords: TIC; Inclusive tourism; Disability; Tourist value chain

Articulo derivado del proyecto de investigación Turismo sostenible del grupo de investigación aprobado por la Dirección de Investigaciones de la Universidad Pedagógica y Tecnológica de Colombia. Grupos de investigación INNTEC y GEVAFI.

* Magister en Administración. Universidad Nacional de Colombia. Administradora de Empresas Universidad Pedagógica y Tecnológica de Colombia. Profesora asociada Universidad Pedagógica y Tecnológica de Colombia. 


\title{
TECNOLOGIAS DE INFORMAÇÃO E COMUNICAÇÃO PARA O TURISMO INCLUSIVO
}

\begin{abstract}
Resumo
O propósito deste trabalho é apresentar as tecnologias de informação e comunicação com potencial para permitir a inclusão de pessoas com incapacidade como clientes dos destinos turísticos. As tecnologias foram identificadas através da busca de informação em bases de dados acadêmicas e páginas web de empresas provedoras de tecnologias de informação para pessoas em estado de incapacidade, indicando como podem ser usadas nas atividades da rede de valor turístico. Encontrou-se que as tecnologias usadas nos campos de entretenimento, educação, saúde e artefatos desenhados para facilitar a vida de pessoas com incapacidade, podem ser utilizados na indústria turística, apoiando-os em funções mentais, sensoriais, de voz e fala, neuromusculoesqueléticas e de movimento.
\end{abstract}

Palavras chave: TIC; Turismo inclusivo; Incapacidade; Corrente de valor turística.

Rodríguez, D. (2018) Tecnologías de Información y Comunicación para el turismo inclusivo. En: Revista de la Facultad de Ciencias Económica: Investigación y Reflexión. rev.fac.cienc. econ, XXVI (1), DOI: https://doi.org/10.18359/rfce.3142

JEL: L86, Z32, Z39.

\section{Introducción}

El sector turístico es uno de los de mayor dinámica en el planeta, con altas tasas de crecimiento, generador de divisas y empleo, el segmento de mercado de personas con algún tipo de discapacidad está en crecimiento lo que puede significar beneficios económicos, adicionalmente el concepto de sostenibilidad indica que los sectores deben estar pendientes no solamente de aspectos monetarios, también de aspectos ambientales y sociales.

En el ámbito social se reclama la igualdad de derechos de todas las personas en todas las actividades que realizan los seres humanos y se habla de inclusión debido a que cada vez hay más personas con dificultades de acceso, así el sector turístico debe progresivamente garantizar el acceso a todas las personas. Las personas con discapacidad física, sensorial y/o psíquica pueden beneficiarse de las tecnologías de información y comunica- ción, para obtener productos y servicios, si todos en conjunto incorporan accesibilidad, por eso el objetivo de este trabajo es la identificación de tecnologías de información y comunicación que puedan facilitar la inclusión de personas en actividades turísticas.

En primer lugar, se presenta el marco de referencia acerca del uso de tecnologías de información y comunicación en el turismo accesible, indicando el concepto y características del sector turístico, su importancia económica, en seguida, el uso de tecnologías de información y comunicación en el turismo, después establece qué es la discapacidad, algunas cifras sobre discapacidad en el mundo y modelos de discapacidad para después hablar de la accesibilidad del turismo y cómo las tecnologías de información y comunicación pueden contribuir con la accesibilidad del turismo, finalmente se presentan las tecnologías identificadas y su aplicación en las actividades de la cadena de valor turística. 


\section{Uso de tecnologías de información y comunicación en el Turismo accesible}

\subsection{El turismo y su importancia económica}

Según la Organización Mundial del Turismo -OMT-, el turismo se debe entender como el conjunto de actividades que realizan las personas durante sus viajes y estancias en lugares distintos al de su entorno habitual, por un periodo inferior a un año, por motivos no relacionados con el ejercicio de una actividad remunerada en el lugar visitado. La industria internacional del turismo es el mayor proveedor de empleos del planeta y cuenta con variedad de actores heterogéneos (Buhalis \& Law, 2008). Es una de las industrias más dinámicas por su importancia en la movilización de personas por todo el mundo y su contribución en términos económicos, ambientales y socioculturales (Ministerio de Comercio Industria y Turismo, 2011); genera oportunidades de negocio, ingresos por divisas, contribuye al ingreso público y privado, estimula la creación de tecnologías y la formación de capital humano (Brida, Monterubbianesi, \& Zapata, 2011).

El sector turístico, es uno de los de mayor crecimiento mundial (Torres \& Merrero, 2014). El arribo de turistas internacionales a escala mundial ha pasado de 25 millones en 1950 a 1.184 millones en 2015, con seis años consecutivos de crecimiento (WTO, 2016), participó con $30 \%$ de las exportaciones de servicios y el $6 \%$ del total de las exportaciones en el año 2014; en 2015 las exportaciones por turismo fueron de US\$1,4 trillones (WTO, 2016). Este sector se ha ampliado y trasformado, de acuerdo con información de Organización Mundial del Comercio, en 1950 los principales destinos eran Italia, Francia, EEUU, Suiza y Canadá con el $71 \%$ de arribos y en 2010 los destinos más deseados fueron EEUU, Francia, Italia, China y España con el 30\% de visitas. (Jimenéz \& Aquilino, 2012).

El sector turístico es complejo, pues comparado con otras industrias tiene gran variedad de actores heterogéneos (Buhalis \& Law, 2008), puede ser considerado un multi sector, no solo tiene que ver con servicios, comprende también otras ramas de la economía como bienes industriales, producción de artesanías, alimentos, etc. (Quintero, Bernal, \& López, 2005). Se caracteriza por su estacionalidad, pues fluctúa en el tiempo y espacio. (Leeuwen \& Nijkamp, 2011). Es una industria intensiva en información, que comprende elementos tangibles $e$ intangibles, los primeros incluyen sistemas de transporte aéreo, marítimo y terrestre (ferrocarril, carretera), alojamiento, servicios hoteleros, alimentos y bebidas, recuerdos, servicios como banca, seguros y la seguridad en el destino (Colak \& Aydinoglu, 2006), también tiene en cuenta el destino y la región en la que se encuentra, además la comunidad que habita el destino (Monterrubio, 2009); los elementos intangibles del turismo incluyen: descanso, relajación, cultura, aventura y experiencias nuevas. (Colak \& Aydinoglu, 2006).

\subsection{Aplicación de tecnologías de información y comunicación en el turismo}

La economía actual se caracteriza por la importancia de las industrias intensivas en información y de la información en sí misma (Weber \& Zink, 2014). La competencia de las empresas para crear valor, ya no depende únicamente de capacidades financieras y de producción, la información es fundamental para lograr mayor productividad e innovación. (Drucker, 1990; Castells, 2001; Norton \& Kaplan, 2000; Toffler, 1990). La información es central para la economía y la sociedad (Weber \& Zink, 2014) y su gestión es realizada y facilitada por las Tecnologías de Información y Comunicación (TIC).

Las TIC hacen referencia a los recursos tecnológicos que permiten el almacenamiento, procesamiento, organización, acceso, uso, distribución y comunicación de información. Comprende recursos informáticos como software y hardware necesarios para almacenamiento y gestión de información, además redes de comunicación a través de diversos medios físicos, que permiten su transmisión. La Tecnología de Información y Comunicación (TIC) comprende el estudio, diseño, desarrollo, implementación, soporte de sistemas de información basados en computadores y aplicaciones de software (Simsek, Altun, \& Ates, 2010). Incluye computadores, teléfonos móviles, personal digital assistant (PDA), internet, páginas web, blogs, chats, cámaras digitales, repro- 
ductores de mp3, mp4, etc., reproductores y quemadores de DVD, GPS y otros (Toboso, 2011).

Desde la década de los 80 las TIC han transformado al turismo, en cuanto a prácticas de negocio y la estructura de la industria (Porter, 2001), también han contribuido con la ventaja competitiva y tienen amplio potencial para transformar la cadena de valor (Porter, 1985). Las TIC inciden en toda la cadena turística, desde el momento en que el posible cliente inicia la búsqueda de información sobre el producto turístico hasta el servicio posventa (Torres \& Merrero, 2014). Las TIC incrementan la sostenibilidad socioeconómica ofreciendo productos más económicos por la disminución del costo en mano de obra, acceso fácil a información a través de la web, el comercio electrónico reduce el desperdicio, puede acelerar la velocidad de introducción de nuevos productos, mejora procesos y reduce demanda de oficinas y locales para comercio (Nicolae \& Sabina, 2012).

Las TIC y especialmente internet afectó las cinco fuerzas del modelo de Porter, pues cambió las condiciones de competencia en el mercado, alteró las barreras de entrada, la cantidad de capital necesario para competir, minimizó los costos, revolucionó los canales de distribución, facilitando la transparencia de los precios y de la competencia, mejoró la eficiencia, aumentado la capacidad de negociación de proveedores y clientes (Buhalis \& Law, 2008, citando a Kim Nam, \& Stimpert, 2004 y Porter, 2001). No hay duda en cuanto a los beneficios que ofrecen las aplicaciones de tecnología de información pues además de reducir costos mejoran la eficiencia operativa y la calidad del servicio (Alforda \& Clarke, 2009).

El turismo es un negocio que requiere gran cantidad de información, su calidad depende de la disponibilidad y gestión de información (Egger, 2006 citado en Puehretmair \& Woess, 2008). Las TIC permiten un mayor volumen y control de los flujos de información entre los vendedores y compradores. Los primeros tienen más información sobre sus clientes y sus operaciones, pueden incorporar servicios complementarios y desarrollar relaciones más complejas, reduciendo costos de transacción, aumentando las relaciones verticales (Nooteboom, 1992 citado en Berne, et al. 2011).

Las TIC también conducen cambios en las relaciones horizontales, generan mayores incentivos para la cooperación entre competidores, como el caso de las asociaciones de pequeños proveedores de servicios turísticos que se agrupan para desarrollar una página web común, ofreciendo una plataforma con menores costos para cada uno, y con mayor oportunidad de ser visitados; también en el ámbito de los intermediarios se pueden ver agrupaciones horizontales incorporando TIC en comercialización y distribución (Berne, et al. 2011). En esta misma dirección Uribe \& Messino (2010), señalan experiencias en Latinoamérica donde las TIC han fomentado la asociatividad y constituyen un facilitador en la construcción de ventajas competitivas.

Internet ha revolucionado la distribución de información de turismo y ventas además tiene un impacto importante como fuente de información para el turismo (Seng, 2015). El desarrollo de redes sociales y TIC han generado importantes cambios en los modelos de comportamiento de los turistas y en la forma en que buscan, evalúan, compran y consumen información, productos y servicios (Bizirgiannia \& Dionysopouloub, 2013). Hoy es común comprar tiquetes aéreos, reservar hoteles y automóviles en línea, en lugar de acercarse a las agencias de viaje tradicionales debido a que las TIC hacen que la oferta y demanda estén cada vez más cerca disminuyendo tiempo de respuesta y costos, acortan el canal de distribución y por tanto las funciones realizadas por las agencias (Barroso \& Flores, 2006).

Los turistas de las principales regiones del mundo se han convertido en viajeros frecuentes, son lingüística y tecnológicamente hábiles y pueden funcionar en entornos multiculturales; se han vuelto más independientes y sofisticados en el uso de una amplia gama de herramientas para organizar sus viajes, que incluyen sistemas de reserva y agencias de viajes en línea, meta buscadores, sistemas de gestión de destinos, redes sociales y portales web, sitios de comparación de precios, además proveedores individuales y sitios de intermediarios (Buhalis \& Law, 2008). Las TIC tienen varios componentes 
de gran utilidad para la industria del turismo que incluyen sistemas de reserva, teleconferencia, vídeo, video folletos, sistemas de información de gestión de información electrónica, aerolíneas, sistemas de transferencia electrónica de fondos, redes telefónicas digitales, tarjetas inteligentes, comunicaciones móviles, correo electrónico e Internet (Seng, 2015).

Las TIC y en especial Internet han convertido a los turistas en individuos bien informados, menos interesados en el seguimiento de las multitudes más dispuestos a seguir sus preferencias (Buhalis \& Law, 2008) también se ha ampliado la participación de los clientes en el diseño de productos turísticos personalizados (Barroso \& Flores, 2006). La transmisión rápida de datos en Internet, ha reducido el tiempo de respuesta lo cual influye positivamente en la satisfacción del cliente, el comportamiento de respuesta se convirtió en un factor esencial para el éxito de las empresas turísticas pequeñas y medianas, además la satisfacción del cliente en línea tiene un impacto positivo en la lealtad tanto a servicios de la organización como a su página web (Main, 2001 y Pechlaner, Rienzner, Matzler, \& Osti, 2002, citados en Buhalis \& Law, 2008).

El desarrollo de recursos multimedia se está convirtiendo en un aspecto clave, para la promoción de turismo, pues la información turística necesita presentación de fotos, gráficos, animaciones y videos para proporcionar una imagen tangible, aumentando la riqueza de la información e interacción virtual con un destino (Cho y Fesenmaier, 2001, citado en Buhalis \& Law, 2008). Los turistas pueden visualizar la información a través de mapas con imágenes aéreas y de satélite, en 2D y 3D. Incluso los atractivos turísticos se pueden presentar de forma dinámica por personajes virtuales en tiempo real (Buhalis \& Law, 2008).

\subsection{La discapacidad}

De acuerdo con el diccionario de la Real Academia de la Lengua Española, el término discapacidad se refiere a la cualidad de discapacitado, que a su vez consiste en que una persona tiene impedida o entorpecida alguna de las actividades cotidianas consideradas normales, debido a la alteración en sus funciones intelectuales o físicas (www.rae.es). La discapacidad está definida como una deficiencia física, sensorial o mental que limita de manera importante actividades normales de una persona (Ozols, 2007). Es toda restricción, limitación, deficiencia de la capacidad física, visual, auditiva, sensorial, mental o intelectual que impide, a quien la padece, realizar una actividad normalmente y participar de manera plena y efectiva en la sociedad, en igualdad de condiciones y oportunidades con otras personas (García, 2015). Una discapacidad puede ser causada por trauma, enfermedades degenerativas o por la vejez (Caulfield, Conway \& Micera, 2012).

El escenario para las personas con discapacidad es desfavorable, hay exclusión, discriminación, marginación, incumplimiento de normas, indiferencia, ignorancia, vulneración de derechos, entre otros (Continuo, 2013), estos individuos tienen dificultades en la realización de diversas actividades en entornos productivos, de servicios y recreativos que no están diseñados para atender sus necesidades y como consecuencia no participan de las dinámicas diarias en igualdad de condiciones. La discapacidad tiene repercusión directa en la persona que la posee en cuanto a la posibilidad de realizar actividades en los términos considerados normales para individuos con características similares, como edad, género, etc. (Egea \& Sarabia, 2001). Tiene consecuencias personales, familiares y sociales, por la condición de dependencia, además las personas con discapacidad, se describen en términos negativos, tienen menores aspiraciones y presentan mayor depresión y ansiedad (Moreno, Rodríguez, Gutierrez, Ramírez, \& Barrera, 2006).

La discapacidad es un fenómeno universal, algunas pueden ser temporales, otras pueden incapacitar a la persona transitoria o permanentemente para alguna labor pero no para otras, también el hecho de habitar en un área rural o urbana modifica el grado de discapacidad, de igual manera, el habitar en países con distintos grados de desarrollo, modifica el grado de discapacidad debido a las condiciones e infraestructura que el ambiente provee (Padilla, 2010). Las características de discapacidad en los países son distintas y también dependen de factores como ambiente, salud, catástrofes naturales, hábitos alimenticios, entre otros (OMS, 2011). 
La discapacidad es parte de la condición de seres humanos, y casi todos la sufrirán en algún momento de sus vidas. Las personas con algún tipo de discapacidad superan el millardo (alrededor de $15 \%$ de la población mundial), cantidad que aumentará de manera importante debido al envejecimiento de la población mundial y al aumento de enfermedades como cáncer, diabetes, entre otras (OMS, 2011). En el año 2009 más de 730 millones de personas tenían más de 60 años, aproximadamente el 10\% de la población mundial (ONU, 2009 citado en OMT, 2014), para el 2020 se prevé que será el 20\% (ONU, 2002). De acuerdo con Naciones Unidas y Banco Mundial, el número de personas con discapacidad para el año 2050 ascenderá a 1200 millones (Domínguez, Fraiz \& Alén, 2015). En Colombia según el Censo, en el año 2005 existían 2.648.898 personas con discapacidad, equivalente al 6,3\% de la población (Gómez, Avella, \& Moralez, 2015). Con una tendencia hacia población más envejecida, muchos prevén un problema cada vez mayor, las personas se están volviendo cada vez más dependientes y la demanda de servicios de atención, para estos individuos, está en aumento (Niemeijer, et al., 2013).

La condición de discapacidad tiene mayor incidencia en países con ingresos bajos y en poblaciones vulnerables, las personas más pobres, con bajos ingresos, con poca formación académica, los ancianos, mujeres, grupos étnicos minoritarios, tienen mayor riesgo de discapacidad; también mayor probabilidad de fracaso escolar con menos oportunidades de ingreso y permanencia en el sistema educativo, mínimas posibilidades de empleo, salarios más bajos, tasas más elevadas de pobreza (OMS, 2011). En Colombia, al parecer, la discapacidad ésta relacionada directamente con la pobreza, el 79\% de las personas con algún tipo de discapacidad, son de estratos 1 y 2 (Parra, 2013).

Las personas en condición de discapacidad poseen mayor riesgo de exclusión y deben realizar esfuerzos adicionales para superar limitaciones (Luque \& Luque, 2012). La exclusión puede depender de la baja capacidad del Estado y la sociedad para establecer estrategias que contribuyan con la mayor participación de todas las personas (Cobo, Sandoval, \&
Alvarado, 2012). Las políticas públicas tampoco incluyen necesidades de personas con discapacidad o las reglas existentes no se cumplen, estos individuos son más vulnerables a las deficiencias en los servicios de salud, además la infraestructura y mobiliario de las ciudades es insuficiente para atender sus necesidades (OMS, 2011). Uno de los objetivos del milenio es proporcionar a todas las personas que presenten alguna discapacidad, una mejor calidad de vida y suprimir los obstáculos que no les permiten tener un trabajo digno, condiciones de acceso a todos los lugares, recibir una educación con calidad $y$ en general otras condiciones de desventaja que se puedan presentar (ONU, 2013).

Hay dos modelos de discapacidad y en cada uno las intervenciones tienen un carácter distinto: el modelo biopsicosocial o médico y el modelo social. En el primero se cree que la discapacidad reside en el individuo y, por lo tanto, las intervenciones se centran en la modificación o adaptación de la persona; el modelo social propone que el entorno crea discapacidad, entonces la intervención debe realizarse en el medio ambiente (Ripat \& Woodgate, 2011).

El modelo médico está especialmente presente en países en desarrollo, se empeña en la rehabilitación de los aspectos funcionales del individuo, considera la discapacidad como una enfermedad que causa una deficiencia en la salud, que demanda asistencia médica continua para recuperarla o mejorarla (UNWTO, 2014), como supone que la cusa de la discapacidad es médica, debe haber atención médica a las personas (Toboso, 2011). La discapacidad desde el modelo biopsicosocial es clasificada en física (o motora) e intelectual. La primera hace referencia a la dificultad para realizar actividades motoras convencionales, debido a dificultades corporales (auditivas, visuales, óseas, etc.). La discapacidad intelectual, corresponde a un desorden de las funciones mentales que afecta a las personas en todos los aspectos mental, físico y social (Benda, Havlícek, Lohr \& Havránek, 2011), tiene que ver con un funcionamiento intelectual inferior a la media, sin embargo, también pueden verse afectados otros aspectos como el motor perceptivo, cognoscitivo, lingüístico, afectivo y social (Abril, 2003). La ONU (2008) establece que las personas con discapacidad 
son aquellas que tienen deficiencias físicas, mentales, intelectuales o sensoriales a largo plazo que, al interactuar con diversas barreras, puedan impedir su participación plena y efectiva en la sociedad, en igualdad de condiciones con las demás.

Las personas con discapacidad mental superan el $3 \%$ de la población (Benda et al., 2011). En lo referente al funcionamiento intelectual, el coeficiente intelectual (CI) ha sido el criterio para catalogar la discapacidad intelectual (DI), clasificada en ligera, moderada, severa y profunda. (Navas, Verdugo \& Gómez, 2008). En la DI leve el CI esta entre 50 y 69 , en la moderada entre 35 y 49, la severa con CI entre 20 y 34 y profunda menor a 20 (OMS 1994 citado en Gutierrez \& Martorell, 2011). Posteriormente se han tenido en cuenta otras dimensiones en la DI que tienen que ver con la interacción con el entorno como conducta adaptativa (habilidades conceptuales, prácticas y sociales que los individuos han aprendido para funcionar en su vida diaria) y roles sociales (Navas et al., 2008).

El modelo social indica que una situación de discapacidad no se produce por una limitación física o psíquica del individuo, sino que es producida por las barreras que la sociedad impone debido a la construcción de un entorno social ajustado a un modelo "normal" o para personas "normales", entonces las medidas no necesariamente deben conducir a rehabilitar al individuo (Ospina, 2010), desde este enfoque el problema no es de la persona, sino que las limitaciones están estimuladas por la sociedad, el entorno que tiene obstáculos y genera desigualdad (UNWTO, 2014). En el modelo social las personas con discapacidad son vistas como cualquier otro, además contempla que la discapacidad es un constructo de la sociedad, la cual está equivocada cuando diseña y construye entornos que no tienen en cuenta las necesidades de todas las personas (Toboso, 2011).

El entorno urbano presenta importantes barreras para las personas con algún tipo de discapacidad, como entradas a edificios sin rampas o estructuras inadecuadas; hay obstáculos arquitectónicos, urbanísticos, incluso en espacios no edificados de dominio público o privado, también barreras en el transporte público y particular, por distintos medios terrestre, marítimo, fluvial y aéreo; la falta de acceso al transporte público es una gran dificultad pues al tratar de conseguir un trabajo o atender una cita médica o simplemente desplazarse por la ciudad, también hay problemas en el acceso a la información, que no satisface las necesidades de comunicación por la dificultad en la comprensión de mensajes visuales, auditivos o gestuales (OMS, 2011).

La formulación de políticas públicas no siempre está dirigida a crear un ambiente que favorezca a los individuos con discapacidad, un ejemplo de ello es que en muchos países no se promueven políticas de inclusión, además se evidencia la falta ayuda y protección social a estas personas, los recursos asignados para formular y ejecutar políticas encaminadas mejorar la calidad de vida para los individuos con discapacidad no son suficientes, entonces son vulnerables a las deficiencias de servicios como salud, educación, transporte, turismo, recreación, entre otras, insuficiencias que se incrementan si se tiene en cuenta que hay escasez en la dotación de las instalaciones en donde se prestan los servicios, además la baja competencia de las personas encargadas de brindarlos; las actitudes negativas, creencias y prejuicios también constituyen obstáculos al generar rechazo en diversas actividades cotidianas como estudiar, trabajar y en general las acciones que forjen integración social (OMS, 2011). Se debe garantizar el derecho a toda persona a la igualdad de oportunidades en espacios laborales, políticos, económicos, sociales, culturales, civiles, etc.; la autonomía personal y acceso universal a los entornos, servicios, procesos, bienes, productos. (García, 2015)

\subsection{El turismo accesible}

Por muchos años la industria del turismo, prestó poca atención a los turistas con discapacidad, pero esto ha cambiado (Sanmargaraja \& Wee, 2015). La investigación en turismo y discapacidad se ha incrementado (Domínguez, Darcy, \& Alén, 2015), ha recibido gran atención por los gobiernos y la academia en la última década en Europa, Américas, Asia y el Pacífico (Bizjak, Knezeevic, \& Cvetreznik, 2011), esta atención creciente es reflejo de la preocupación por derechos de las personas con 
discapacidad (Pagán, 2012). Los individuos con discapacidad, al igual que el resto de personas, tienen el mismo derecho a disfrutar del turismo (Packer, McKercher \& Yau, 2007) y con la ratificación de la Convención de las Naciones Unidas sobre los derechos de las personas con discapacidad, el sector debe estar atento a garantizar que las personas con discapacidad ejerzan su derecho en igualdad de condiciones que el resto de ciudadanos (OMT, 2014).

El turismo accesible se denomina también turismo inclusivo, sin barreras, para todos, turismo de fácil acceso, turismo universal (UNWTO, 2014). El término turismo accesible o para todos, fue utilizado por primera vez en 1989 en el Reino Unido y se refiere a la eliminación de barreras urbanísticas, arquitectónicas y sociales, para personas con alguna discapacidad en actividades turísticas (Jurado, 2014). El turismo para todos tiene el objetivo de asegurar que todo el sistema turístico como el transporte, alojamiento, destinos, satisfacen las necesidades de las personas con discapacidad (Domínguez, et al., 2015).

El turismo inclusivo comprende el "conjunto de actividades realizadas durante el tiempo libre dedicado al turismo por personas con capacidades restringidas, que les posibilita su plena integración desde la óptica funcional y psicológica, obteniendo la plena satisfacción individual y social". (Grünewald, L. et al. (1996), citado en UNWTO, 2014, p. 17). El objetivo es que estos individuos participen en la oferta turística eliminado las barreras en los entornos de servicio. Este concepto ha sido ampliado teniendo en cuenta no sólo a las personas con discapacidad, sino a todos los individuos, independientemente de sus condiciones (niños, ancianos, familias con bebes, mujeres embarazadas, personas con lesiones temporales, personas con bajos ingresos, jóvenes, etc.), así las condiciones de accesibilidad repercuten en la totalidad de la población (UNWTO, 2014). No sólo las personas con alguna discapacidad se benefician de la accesibilidad en el turismo, también lo hacen, por ejemplo, familias con niños pequeños y personas con discapacidad transitoria (Domínguez, et al., 2015). Se debe garantizar que los destinos turísticos sean accesibles para todas las personas, independientemente de sus limitaciones físicas, discapacidad o edad.
El turismo accesible se basa en la filosofía del diseño para todos, es decir, diseñar para personas con y sin discapacidad (Puehretmair \& Woess, 2008). El concepto del diseño para todos se introdujo en la década de los ochenta por el arquitecto Ronald Mace y ha sido adoptado en diversos campos (Røssvoll \& Fuglerud, 2013). La accesibilidad universal se refiere a la condición de los entornos, procesos, productos, servicios, objetos, instrumentos, herramientas, dispositivos, etc. para ser comprendidos y utilizados por todos de manera cómoda, natural, autónoma y segura, lo cual requiere que el diseño desde el principio tenga en cuenta la funcionalidad de las personas, cabe notar que los criterios de diseño dependen también del entorno y del avance tecnológico (AENOR, 2007), sin embargo este proceso es difícil en la práctica en cuanto a la determinación de requisitos y la realimentación con este segmento poblacional (Scott, Spyridonis \& Ghinea, 2015), dependiendo de la naturaleza de la discapacidad las técnicas de diseño se hacen difíciles de usar, en el caso de diseño de TIC, no existe técnica algunas de diseño para individuos con discapacidad (Dekelver et al., 2015), los diseñadores deben superar éstas limitaciones, pues el turismo accesible es un derecho social y significa facilitar el acceso para las personas, sin importar género, edad, condiciones físicas, etc. con el objetivo del disfrute de experiencias turísticas (Menzel \& Weldig, 2011).

El turismo inclusivo implica que la accesibilidad debe estar en toda la cadena de valor, desde la gestión del destino, información y publicidad, en entornos arquitectónicos y urbanísticos, medios de transporte y estaciones, alojamientos, servicios de restaurante, actividades culturales y recreativas (Calvo, Navarro, \& Periañez, 2015). El turismo accesible es una responsabilidad social, todas las personas con alguna discapacidad tienen la misma libertad que las otras personas de disfrutar del turismo; acceso a la información, la movilidad en cualquier parte de toda la cadena de valor, desde reservar una habitación de hotel con las condiciones necesarias para suplir necesidades especiales, comprar un tiquete, registrar equipaje en un avión, uso de transporte, participar en eventos culturales y deportivos (Ivanović, 2015). 
Un entorno accesible debe ser respetuoso de la diversidad, seguro y saludable, funcional, comprensible y estético; la norma española UNE 1700011:2007 establece 4 criterios de accesibilidad en un entorno, deambulación, aprehensión, localización y comunicación (Calvo et al., 2015). La deambulación es la acción de desplazamiento de un lugar a otro, horizontal (por calles, pasillos, corredores, etc.) y verticalmente (escaleras, rampas, ascensores); La aprehensión, es la acción de coger una cosa, de alcanzarla. La localización que se refiere a la acción de indagar el lugar o momento preciso en el que está algo, alguien o puede acontecer un suceso y la comunicación, que consiste en la acción de intercambio de la información para desarrollar una actividad. (AENOR, 2007)

El turismo inclusivo requiere de la cooperación de planificadores regionales y de ciudades, de la industria del turismo, de proveedores de transporte público y privado, arquitectos y constructores, sistemas de salud, restaurantes, guías turísticos, tiendas, negocios de entretenimiento, etc. (Coppola et al., 2012). El éxito del turismo depende de la infraestructura a lo largo de la cadena de valor y debe dar respuesta a las necesidades de las personas con discapacidad, bebes, adultos mayores, etc.

Las personas con discapacidad tienen las mismas necesidades, motivaciones y deseos para viajar que el resto de la población (Kascak, Lee, Liu, \& Sanford, 2015), sin embargo, no viajan con la misma frecuencia, si se hace la comparación con viajes turísticos de personas sin discapacidad (Packer et al., 2007). Los turistas con discapacidad hoy se enfrentan a barreras que hacen difícil o impiden el acceso y disfrute de actividades turísticas en todo el ciclo, transporte, alojamiento, agencias de viajes, restaurantes, información, reservas, barreras urbanas, arquitectónicas y de sensibilización, etc. (Calvo et al., 2015). La realidad indica que las experiencias de viaje para personas con discapacidad son afectadas negativamente por la inaccesibilidad al alojamiento, transporte e infraestructura y baja calidad en los servicios por inadecuada asistencia, además diseño no accesible en las páginas web y materiales informativos (Pühretmair, 2004 citado en Puehretmair \& Woess, 2008).
Existen tres tipos de barreras para las personas con discapacidad: las barreras intrinsecas que se refieren a la funcionalidad física, psicológica y cognitiva de cada individuo; barreras ambientales impuestas por las condiciones del entorno en arquitectura, transporte, comunicación, y actitudes de rechazo; finalmente las barreras interactivas, relacionadas con la capacidad requerida para actividades de comunicación e interacción con las personas y el entorno (Martín \& González, 2003 citado por Calvo et al., 2015). En turismo las restricciones existentes para personas con discapacidad son magnificadas por las deficiencias en energía y la restricción en tiempo, pues se requiere un mayor periodo para realizar actividades, otras limitaciones son la dependencia de otros y la preocupación por la seguridad tanto física como psicológica (Packer et al., 2007).

Las principales inquietudes de los turistas con discapacidad, cuando realizan vacaciones, son entre otras, la accesibilidad del aeropuerto, estaciones de tren, transporte en silla de ruedas en el lugar de destino, habitaciones adaptadas, información fiable acerca de la accesibilidad del destino y sitios de interés como iglesias, museos, monumentos, etc. baños accesibles, restaurantes y bares accesibles, paso a zonas peatonales, disponibilidad de equipos de la discapacidad, el alquiler como sillas de ruedas (Menzel \& Weldig, 2011). En estudio realizado con 59 personas con discapacidad en España, se estableció que la mayoría de ellos encuentra mayor dificultad al moverse en las ciudades, enseguida en los hoteles, después transporte público y finalmente líneas aéreas. En los hoteles la mayor dificultad está en las escaleras, después el personal y finalmente aceras (Suriá \& Escalona, 2004)

La sociedad tiene la responsabilidad de proporcionar apoyo y medios que permitan su integración (Oliver, Sancho, \& Galiana, 2012). Si se proporciona un entorno sin barreras, con personal especializado, las personas con discapacidad pueden lograr experiencias similares o iguales que el turista medio (Wu \& Cheng, 2008). 


\subsection{El turismo accesible y tecnología de infor- mación y comunicación}

La tecnología desempeña un importante papel en cualquier tipo de trabajo (Benda et al., 2011), Las TIC, afectan la vida de las personas, modifican sus acciones hacen posibles nuevas acciones (Toboso, 2011). El avance tecnológico en términos generales (TIC, biotecnología, nanotecnología, ingeniería biomédica etc.), ha permitido la prevención de discapacidad con el tratamiento de enfermedades desde la gestación, también ha contribuido con tratamientos de terapia (Wise, 2012) y por supuesto con la inclusión. La tecnología se usa para la supervivencia o prolongar periodos de vida de las personas (Nicholl, Doyle \& College, 2013), también permite adaptarse mejor a ella.

Más de 2 mil millones de personas en todo el mundo tienen diferentes tipos, grados, o combinaciones de discapacidad y niveles de alfabetización digital que les impiden el uso de las TIC (Comunello et al., 2015). personas que no posean habilidades para el uso de TIC están expuestos a la exclusión, especialmente las personas con discapacidad (Dekelver et al., 2015). Las TIC pueden ser usadas para hacer frente a muchas situaciones de discapacidad, por ejemplo el uso de un chip para reducir problemas del sistema nervioso y disminuir movimientos erráticos característicos de algunas enfermedades del sistema nervioso (Busby, 2006). Las TIC deben ser cada vez más accesibles y compatibles con los dispositivos de apoyo técnico para personas con discapacidad, de esta manera traen beneficios y oportunidades para la educación, el empleo, el ocio, y la participación en sociedad (Toboso, 2011).

La publicación de investigaciones acerca del uso de TIC en personas con discapacidad mental y su exclusión de la sociedad de la información, son escasas comparadas con publicaciones acerca de discapacidad física y tecnología (Dekelver et al., 2015). Varias investigaciones han demostrado las posibilidades de las TIC para personas con discapacidad intelectual, mejorando sus actividades diarias, independencia y calidad de vida (Li-Tsang et al., 2007).
El turismo accesible también utiliza ampliamente las TIC para sus objetivos de marketing. (Ivanović, 2015). Y aunque la tecnología no logra ayudar con todo, puede aumentar muchas áreas de la independencia (Zhang et al., 2012), por ejemplo, las redes sociales proveen participación y aprendizaje, la conexión a través de las redes de comunicación es un instrumento que proporciona a las personas con discapacidad inclusión y el desarrollo de algunos aspectos de su vida (Altinay et al., 2016). Los adolescentes son fuertes consumidores de información y TIC, participan intensamente en comunicaciones como mensajería, mails, blogs, redes sociales, foros; comparten juegos, fotos, videos; el uso de TIC cumple un papel importante en el desarrollo social $y$ emocional de los jóvenes (Schreuer, Keter, \& Sachs, 2007).

Con las TIC los proveedores turísticos han ampliado el público, más clientes, con información personalizada, en mayor cantidad, y con aumento de la agilidad que permite a los consumidores turistas adquirir diversos servicios a través de la web, sin embargo, para personas con discapacidad visual, auditiva, cognitiva o de movilidad el acceso a la información puede ser problemático (OMT, 2015). Las personas con discapacidad tienen requisitos muy especiales relativos a la capacidad de uso de los sistemas de información de turismo, basadas en la Web, debido a la heterogeneidad de las discapacidades, aunque a veces diferentes discapacidades requieren soluciones similares (Rumetshofer \& Wolfram, 2004).

La personas con discapacidad física, sensorial y/o psíquica pueden beneficiarse de las TIC para obtener productos y servicios si éstos incorporan accesibilidad, así sujetos con dificultades en la coordinación de extremidades tienen dificultad para usar teclados, mouse o personas con problemas visuales $y / o$ auditivos no tienen acceso a contenido visual y/o sonoro que proporcionan los computadores y la web (García \& Rodríguez, 2000). La información turística debe ser perfilada bajo los principios de diseño universal, así puede ser usada por todas las personas sin importar su condición; adicionalmente es necesaria mayor información confiable y actualizada acerca de la accesibilidad de servicios turísti- 
cos, infraestructura, instalaciones, disponibilidad de servicios de apoyo, etc. (OMT, 2015).

El uso de TIC necesita ciertos conocimientos y competencias que pueden ser difíciles de adquirir para personas con algunas discapacidades (Gutierrez \& Martorell, 2011), por eso deben ser entrenadas en su uso, se ha comprobado que las personas con discapacidad intelectual mejoran el uso de TIC, con entrenamiento y uso continuo (Li-Tsang et al., 2007; Li-Tsang et al., 2004)participants were taught about the operations of mouse and keyboard and browsing the Internet using Internet Explorer (IE. El acceso a la web no sólo depende de los contenidos accesibles, también sobre el uso de browser $y$ otras interfaces de usuario (Altinay et al., 2016).

\section{Las tecnologías de información y co- municación y posibilidades de uso en el turismo inclusivo}

En primer lugar, se presenta la clasificación internacional de funcionamiento, de la discapacidad y la salud de la OMS para establecer los tipos de discapacidad que pueden ser atendidos con tecnologías de información y comunicación en el ámbito turístico.

La OMS (2001) construyó la clasificación Internacional del funcionamiento, de la discapacidad y de la salud (CIF), que proporciona una base científica para el estudio de la salud de todos incluyendo personas con discapacidad, provee descripción del funcionamiento humano y sus restricciones, está organizada en dos partes: La primera (1) Funcionamiento y discapacidad, que incluye (a) funcionamiento y estructuras corporales y (b) actividades y participación; la segunda (2) factores contextuales, que comprende (c) factores ambientales y (d) factores personales. Las funciones corporales (a), son las funciones fisiológicas de los sistemas corporales, como las funciones de los sentidos, incluye también funciones psicológicas; las estructuras corporales corresponden a la anatomía como órganos, extremidades y sus componentes. Las deficiencias en la estructura pueden ser anomalías, defectos, pérdida o desviación en las estructuras del cuerpo humano, de acuerdo con la norma biomédica aceptada (OMS, 2001).
La CIF clasifica funciones corporales en: funciones mentales; funciones sensoriales y de dolor; funciones de la voz y el habla; función de sistemas cardiovascular, hematológica, inmunológica y respiratoria; funciones de los sistemas digestivo, metabólico $y$ endocrino; funciones neuromusculoesqueléticas, y relacionadas con el movimiento; funciones de la piel y estructuras relacionadas y las correspondientes estructuras corporales en: estructuras del sistema nervioso; ojo, oído y estructuras relacionadas; estructuras involucradas en la voz y el habla; estructuras de los sistemas cardiovascular, inmunológico y respiratorio; estructuras relacionadas con los sistemas digestivo, metabólico y endocrino; estructuras relacionadas con el sistema genitourinario y el reproductor; estructuras relacionadas con el movimiento y piel y estructuras relacionadas (OMS, 2001).

Las personas pueden presentar limitaciones en la realización de actividades y restricciones en la participación en situaciones como aprendizaje y aplicación de conocimientos, tareas, comunicación, movilidad, autocuidado, vida doméstica, interacciones y relaciones interpersonales, vida comunitaria, social y cívica, áreas principales de la vida. En los factores contextuales se encuentran los ambientales que implican los ambientes físico, social y actitudinal, que tienen influencia en el desempeño del individuo en la vida social y capacidad funcional y estructural de su organismo; los factores ambientales tienen dos niveles el individual que es el entorno inmediato de la persona, la casa, el trabajo, la escuela, incluye las características físicas del ambiente y el contacto con las personas, el segundo nivel es el social que comprende estructuras sociales y culturales que afectan a las personas en el entorno laboral, actividades en comunidad, gobierno, servicios de comunicación y transporte, normatividad. Los factores personales son característicos de la persona, como sexo, raza, edad, hábitos, educación, profesión, aspectos psicológicos, etc. (OMS, 2001).

Las TIC pueden facilitar el acceso de personas con discapacidad en funciones mentales, funciones sensoriales, de voz y habla, funciones neuromusculoesqueléticas y de movimiento y en todas las limitaciones y restricciones presentadas en el CIF. A continuación, se muestran las TIC identificadas que 
pueden contribuir en el acceso para personas discapacitadas en la cadena turística, así como el tipo de discapacidad que pueden asistir.

El transporte es una de las principales barreras para personas con discapacidad. Caminar es una forma de transporte, pero hay limitación cuando las distancias son largas, además se deben tener en cuenta aspectos de seguridad, como encontrarse con extraños, perderse, rutas de acceso para personas con discapacidad física, cruce de calles, etc., estas necesidades pueden ser mitigadas con teléfonos celulares con características especiales utilizando georreferenciación, con aplicaciones diseñadas para personas con discapacidad o dificultades cognitivas y físicas, existen, entre otros, jitterbus, firefly, ablelink, doro y phone easy, así la tecnología de sistema de posicionamiento global GPS ofrece gran potencial para la movilidad de personas con discapacidad (Stock et al., 2011).

La tecnología GPS es usada en aplicaciones de software especialmente diseñadas para personas con discapacidad, integradas a teléfonos celulares, Ablelink (http://www.ablelinktech.com/) es una interfaz, con varias aplicaciones, desarrollada para personas con discapacidad intelectual o para la tercera edad, que permiten el uso de herramientas de software instaladas en cualquier Smartphone, la función es mantenerlos conectados a familiares, amigos, cuidadores y profesionales médicos; $W a-$ $y$ Finder, es un dispositivo GPS diseñado para asistir desplazamientos, pueden crearse rutas personalizadas y guía al usuario paso a paso con instrucciones visuales y de voz, mientras que los cuidadores se mantienen actualizados en cuanto a la ruta. Los usuarios deben ser previamente entrenados para su uso y pueden ser usados en el turismo como guías de rutas turísticas, tours, transporte, seguridad, también en lugares de alojamiento y en general para el desarrollo de productos turísticos que deben estar geo referenciados para poder hacer uso de ésta tecnología.

La tecnología GPS es usada también para diseñar productos para personas con discapacidad visual, la Universidad de Colorado trabaja en un proyecto llamado "Movility for All" utilizando tecnología GPS para el tránsito en transporte público, el prototipo provee pistas auditivas y visuales para apoyar actividades como abordar el bus, cuando bajar, a dónde ir, también realiza control de viaje, detección de errores, sin embargo, se requiere de la cooperación de proveedores de servicio lo cual restringe la oportunidad de uso (Stock et al., 2011).

Otra tecnología que puede ser utilizada para el acceso en el turismo son los dispositivos de localización como Brickhouse Child Locator, diseñado para localizar a niños en parques o lugares públicos cuando se alejan de sus padres, quienes llevan un dispositivo que emite una señal a una unidad de control cuando la persona se mueve más allá de un rango designado; otros sistemas más adecuados para personas con limitaciones cognitivas son Spark Nano Tracker, Livewire FastTrak, Community Sidekick or KoolTrax systems, dispositivos (similares a teléfonos celulares) que proporcionan información sobre localización con enlace a un mapa en la web, que es revisado por la persona autorizada con acceso mediante e mail o teléfono celular (Stock et al., 2011)

Los servicios de salud en algunas zonas de Japón son prestados a través de teléfonos (Raku-Raku) de fácil uso diseñados para todos, incluidas las personas de edad avanzada, individuos no familiarizadas con la operación de telefonía móvil y personas con discapacidades físicas, tiene características de administración de la salud, tales como un podómetro incorporado (dispositivo electrónico que cuenta los pasos de cada persona para detectar movimiento de cadera) y medidor de frecuencia cardíaca, conectado a un medidor de presión arterial a través de infrarojo, así se compilan y analizan datos médicos en forma gráfica. Los datos se analizan y luego proporciona consejos de salud para el usuario (Obi, Ishmatova, \& Iwasaki, 2013). Esta tecnología puede ser útil en el turismo para monitorear el estado de salud de las personas en los hoteles y brindar tranquilidad a los cuidadores, también tiene gran potencial de uso en el turismo médico.

En lo referente a limitaciones en la realización de actividades y restricciones en la participación hay software que permite a las personas mayor acceso a la vida social y autonomía. Se usa tecnología como 
celulares con aplicaciones para recordar actividades rutinarias, paso a paso, para personas con problemas de memoria o lesiones cerebrales (Lancioni, et al., 2014), por ejemplo, Visual Impact de ablelink, presenta tutoriales paso a paso para realización de diversas tareas, de manera autónoma, como hacer un café, ensalada, limpiar la casa, aprender habilidades personales, tomar su presión arterial, etc. también puede crear tareas personalizadas guiadas paso a paso por voz e imágenes; la aplicación endeavor permite organizar el día programando tareas y haciendo seguimiento (tomar la medicina, lavarse los dientes, dormir, hacer una tarea, alimentar al perro, etc.); Endeavor Desktop Pro es una interfaz para el sistema operativo Windows que proporciona entorno personalizado adaptado a necesidades y capacidades del usuario para acceder a correo electrónico, web y programas de ordenador (http://www.ablelinktech.com/).

También es posible capacitar a las personas a través de sesiones multimedia y de simulación (Stock et al., 2011), ablelink ofrece aplicaciones como Everyday skills con sesiones de aprendizaje multimedia paso a paso de habilidades para vivir en forma independiente, habilidades sociales apropiadas en ciertos contextos, para personas con autismo u otras discapacidades cognitivas, como restaurantes, peluquerías, tiendas, bibliotecas, lavanderías, lavar platos, cuidado de mascotas, visita al consultorio médico o dentista, comedor, viajar a larga distancia, entre otras. Living safely es otra aplicación con los mismos principios y plataforma, cuyo objetivo es que las personas aprendan a vivir de manera segura, como seguridad en el baño, cocina, incendios, disposición de basuras, extraños en el hogar, etc. (http://www.ablelinktech. com/). En estudio realizado a 59 personas con discapacidad intelectual, entre 18 - 55 años, cuyo objetivo fue entrenarlos en uso del mouse, teclado y acceso a internet, se concluyó que los usos más comunes de las TIC son entretenimiento, productividad y aprendizaje; también son usadas para ocio y entretenimiento (Li-Tsang et al., 2007). Las empresas turísticas pueden crear tutoriales como forma de capacitación para uso de páginas web, reservas, etc.

Universal Desing for Learning (UDL) es un marco de referencia para diseño instruccional, basado en la neurociencia, es flexible y para todo tipo de estudiantes incluidos los que tienen condición de discapacidad cognitiva, así que permite la inclusión de éstas personas en el aula de clase, creando currículos con múltiples medios de representación de información y conocimiento, variados medios de expresión para que los estudiantes demuestren sus conocimientos y diversas formas de comprometer y motivar al estudiante para aprender (Hall, Cohen, Vue, \& Ganley, 2015). Este marco puede ser utilizado en la industria del turismo para generar materiales publicitarios y de promoción de los destinos turísticos.

Curriculum Based Measurement (CBM), consiste en un conjunto de procedimientos que monitorea el aprendizaje y crecimiento de competencias académicas básicas del estudiante mediante la observación directa y el registro de su desempeño, información que permite tomar decisiones instruccionales (Hall et al., 2015). Cada semana se realizan pruebas al estudiante, cuya duración no excede los $5 \mathrm{mi}-$ nutos, el profesor revisa, califica y compara con el desempeño esperado para ese año y con las otras pruebas, generando gráficas que permiten el seguimiento del desempeño (Mclane, 2007). Este tipo de procesos y tecnología pueden ser usados para comunicación con las personas con discapacidad cognitiva para verificar el grado en que comprende la información sobre el destino turístico, mercadeo y compras en línea.

Otro campo de investigación es la robótica, por ejemplo en Instituto Nacional de ciencia y tecnología industrial avanzada de Japón que investiga sobre interacción cognitiva y emocional con robots con formas de animales para personas con Alzahimer y otros tipos de demencia; también se han desarrollado, en la Universidad de Tokio, prototipos de robots recordatorio, uno de estos contabiliza cada movimiento que hace que su propietario y le da una advertencia verbal si una persona intenta tomar la misma acción dos veces. Otro robot recordatorio monitorea una habitación con cámaras y sensores para realizar un seguimiento de objetos pre-registrados, para conducir al usuario a lugares en la habitación (Obi et al., 2013), lo cual puede ser de utilidad en recintos turísticos cerrados y hoteles. 
También hay tecnologías de reconocimiento de voz automático que se han incorporado a dispositivos PDA, debido a la necesidad de teclados con más funciones y las limitaciones de los teclados muy pequeños (Cook, 2008), hoy también se usan dispositivos de acceso para personas con discapacidad física como como pantalla, grandes teclados, emuladores de ratón y punteros que sin duda tienen utilidad para personas con discapacidad motora, así en un caso de estudio de una joven con artritis juvenil, que utiliza computador portátil operado con un procesador de texto con reconocimiento de voz para aprendizaje y socialización (Ratliffe, Rao, Skouge, \& Peter, 2012). El mercado ofrece diversos gadgets de acceso al computador para personas con limitaciones en funciones neuromusculoesqueléticas, por ejemplo, cascos con una vara para teclear para personas que únicamente tienen control de movimientos de la cabeza, otro mecanismo de uso similar es el Sip/Puff Switch que permite el control de diversos dispositivos mediante un tubo conectado a la boca que reconoce movimientos de la lengua y la respiración como señales de encendido y apagado, otros dispositivos externos leen los movimientos de cabeza de la persona con electrodos y giroscopios que se transmiten al computador, también hay sensores de alerta para la cama o silla de ruedas que informa al cuidador por wi-fi de movimientos inusuales o por el contrario de la ausencia de movimiento (http://www.youngmarketing. co). Tecnologías ventajosas para acceder a contenido de marketing turístico en la web para personas con dificultades en la movilidad.

Otro ejemplo de soluciones de asistencia para personas de edad fue ofrecido por el Instituto de Investigación de Sistemas Inteligentes del Instituto Nacional de Ciencia y Tecnología Industrial Avanzada (AIST) de Japón, que desarrolló sistema que permite a las personas con discapacidad combinar diversas ayudas, se utiliza una red común para diferentes módulos robóticos permitiendo la cooperación, el sistema puede estar equipado con una interfaz de respuesta gestual basada en visión estéreo, que puede ser personalizado de acuerdo con el nivel de movilidad del usuario, una interfaz de reconocimiento de voz que puede activar ruedas disponibles en muebles y equipos del hogar para facilitar su mo- vimiento y ayudar a las personas con discapacidad motriz (Obi et al., 2013).

Una tecnología muy interesante y de gran potencialidad para asistir la discapacidad motriz es la tecnología de interfaz entre cerebro y computador que permite comunicar señales cerebrales como los ritmos sensorio motores para personas con discapacidad motora (Arboleda, Garcia, Posada, \& Torres, 2009). Hoy existen en Japón robots de asistencia para caminar, ofrecen movilidad a personas con discapacidad, uno de ellos es el robot Suit Hal (Hybrid Assistive Limb), un robot tipo ciborg que amplia y mejora capacidad física, las señales bio-eléctricas que son enviadas desde el cerebro a los músculos son capturados a través de un sensor conectado a la piel de un usuario, luego se usa una unidad de potencia que proporciona un movimiento de forma simultánea con el movimiento previsto por el usuario (Obi et al., 2013).

Las aplicaciones robóticas para discapacidad motora ya están disponibles en el mercado, producto de la investigación japonesa, se ofrece una silla de ruedas robótica que al encontrar un obstáculo en el camino, las ruedas se transforman en un dispositivo que simula la actividad de las piernas y el usuario indica la dirección e movimiento mediante un joystick para que el robot evalúe el terreno y se adapte a este (http://www.youngmarketing.co/). La robótica puede ser útil para evadir insuficiencias en infraestructura de destinos turísticos, en recorridos turísticos, desplazamiento por las ciudad o diversos terrenos.

Dispositivos eléctricos dan soporte a personas que no pueden expresar sus pensamientos a través del lenguaje hablado llamado Voice output comunication aid (VOCA) (Torii et al., 2013). También se han desarrollado pantallas que reconocen el movimiento de la retina (Cook, 2008), o que pueden convertir el movimiento de los ojos en el cursor del mouse, permitiendo navegar en el computador (http://www. youngmarketing.co). Por otra parte se está desarrollando tecnología que reconoce la sonrisa como respuesta, de esta manera las personas pueden seleccionar una opción en alguna situación, cuando no es posible emitir sonidos vocales o mover los dedos, 
sin embargo, la tecnología para reconocimiento de este tipo de respuestas es muy costosa (Lancioni et al., 2014).

Para personas con limitaciones en estructuras involucradas en la voz y el habla, hay software que decodifica caracteres y gráficos en palabras y frases de forma escrita y auditiva, mediante lectores de pantalla que convierten lo que aparece escrito en la pantalla en sonido, así personas con dificultades visuales pueden acceder a la información, un ejemplo es el Endeavor talker que es un software que convierte un dispositivo Tablet o computadora en un sistema de comunicación de fácil uso (dispositivo $\mathrm{AAC}$ ) que proporciona a las personas que no pueden hablar la capacidad de comunicarse tocando botones con gráficos, con palabras y frases comunes, también es posible personalizar la aplicación creando botones con imágenes de una galería pre establecida o con su propia biblioteca de imágenes, también programar palabras y frases con digitalización de voz o texto (http://www.ablelinktech. com/). Las empresas de la cadena turística pueden usar esta tecnología para acceso a páginas web o selección de opciones en restaurantes y similares o para identificar preferencias en reserva, selección de habitaciones y todo tipo de servicios.

Internet usa estímulos proporcionados por información a través texto, audio, imágenes y video, la interacción se realiza mediante interfaces software y artefactos como mouse, teclado, voz, webcam, cursores (trackball), mouse de gran tamaño que pueden ser operados con las manos o los pies. Algunas personas requieren que se conviertan los estímulos visuales a estímulos táctiles y audibles, lo cual aún es complejo y muy incipiente en cuanto a imágenes estáticas y dinámicas (Ulbricht et al., 2012). Los videojuegos son tecnología de información que ha sido utilizada para la salud. En Japón se ha construido un parque de juegos de rehabilitación que usa videojuegos para ayuda a los ancianos a mantener su salud física y mental, la universidad de Kyushu lidera un proyecto que consiste en un videojuego para rehabilitación llamado "Rehabilium" que utiliza tablero Nintendo wii fit, para que el jugador interactúe con los elementos de control en la pantalla, con sus pies, usa tecnología bluetooth y sensores para iden- tificar cambios en el movimiento (Obi et al., 2013). Para la promoción de destinos turísticos a través de la web puede ser usada la realidad aumentada y la realidad virtual, utilizadas en los videojuegos para aplicaciones a través de la web, para computadores de escritorio, con acceso desde Smartphones (Android, Iphone), Tablet (Android, Ipad), aplicaciones internet (Göksu \& Atici, 2013).

Para personas con discapacidad visual usan los teclados e impresoras Braille, la información turística y material de promoción puede imprimirse en braille y los teclados permiten el acceso a contenidos web de operadores turísticos. Para desplazarse en exteriores, estas personas pueden hacer uso de tecnología GPS a través de PDA y teléfonos celulares que expresan verbalmente las rutas y obstáculos presentes en el entorno, puntos de interés como atractivos turísticos, centros comerciales, restaurantes y en general lugares que ofrecen servicios vinculados con el turismo. También hay juegos como monopolio con tableros, cartas y billetes braille (http:// www.youngmarketing.co), que pueden disponerse en hoteles, restaurantes, etc., para entretenimiento. El sistema de reconocimiento óptico de caracteres (OCR), que desde hace más de una década es utilizado para reconocer texto e imágenes texto, reproduce la información con sintetizador de voz.

Para personas con discapacidad auditiva se usa la tecnología speech to tect conversation que convierte en texto lo que se habla y viceversa. Se dispone de artefactos alarmas con vibración que informa horarios de actividades, timbres que envían señales a través de wi fi a un receptor que emite luz, también se utilizan las señales luminosas para avisar que el teléfono fijo está sonando, existen dispositivos para comunicación escrita con pantalla que transmite mensajes escritos a otros dispositivos compatibles a través de línea telefónica, software que traduce formato texto a lenguaje de señas; en Colombia se desarrolló una plataforma que traduce lenguaje de señas, un avatar gesticula las señales (http://www. youngmarketing.co).

El uso de colores que indican acciones que se deben o no ejecutar, como en el caso del semáforo, pueden ser usados para percibir el espacio y dismi- 
nuir pérdida de autonomía en la vivienda o en otros espacios o para señalar caminos y evitar perderse, personas con discapacidad cognitiva los pueden usar para orientarse y comprender a donde ir y a donde no, el color también puede ser usado para indicar objetos peligrosos o que deben ser manipulados con precaución; existen materiales crómicos inteligentes que cambian de color como respuesta a estímulos ambientales como calor, humedad, presión, luz, electricidad, etc., que pueden ser usados para brindar información preventiva, otra manera es utilizar la intensidad de la luz o destellos o LED; los códigos de colores están siendo utilizados en prototipos de muebles para personas con discapacidad, integrando luz para ayudar a localizar objetos sobre los muebles, además son capaces de comunicarse con otros dispositivos como cortinas, calefacción, iluminación, caminos de luz, constituyendo un centro de comando demótico (Delvigne et al., 2011), esta tecnología puede ser utilizada en los hoteles y atractivos turísticos como museos $e$ incluso en recorridos al aire libre para guiar a los turistas $y$ en general para complementar la infraestructura turística en el aspecto de señalización.

Las TIC hacen posible la inclusión de todas las personas en cada eslabón de la cadena de valor turística y aunque algunos dispositivos y tecnologías aún son costosas, la industria turística debe necesariamente incorporarla si quiere ser sostenible y atender las necesidades de la sociedad y de sus clientes.

La cadena de valor es una herramienta para análisis de competitividad, (Porter, 1991), la presenta como un conjunto de actividades interdependientes, que corresponde a cada uno de los procesos empresariales, dividiéndolos en actividades primarias que permiten a la el desarrollo del propósito empre- sarial y actividades de apoyo para el desarrollo del propósito. Son todas las actividades necesarias para la producción de un bien o servicio desde su concepción hasta la entrega al consumidor (Kaplinsky \& Morris, 2000). El turismo involucra un complejo conjunto de servicios complementarios y de bienes ineludibles para la producción de servicios, que se prestan simultáneamente en el destino turístico (Ventura, 2011).

En la cadena de valor turística las actividades primarias son (1) Creación de productos (como rutas y circuitos turísticos y planes turísticos), (2) Promoción (publicidad, ferias turísticas, relaciones con los medios de comunicación, intermediarios y operadores turísticos), (3) Logística interna (servicios de acogida y transporte, formalidades de entrada y salida, manejo de equipaje y seguridad; (4) Servicios del destino atractivos turísticos, alojamiento, gastronomía, tours, itinerarios, recorrido, actividades de recreación, alquiler de vehículos e información turística y (5) servicios posventa (gestión de información, seguimiento del cliente); las actividades apoyo son (a) planificación de destino e infraestructura (transporte, electricidad, agua, señalización, residuos); (b) gestión de recursos humanos (sensibilización y actitud positiva hacia el turista, capacitación al personal y creación de puestos de trabajo); (c) desarrollo de recursos y productos (mejora ambiental, aprovechamiento de nuevos mercados y segmentos y sistemas de calidad) y (d) tecnologías y sistemas de información como conexión a internet y redes telefónicas, investigación de mercados, sistemas de reservas informatizados (Jonker, 2004 citado en Reguera \& López, 2014). En la imagen se presentan los aportes de las TIC en la cadena de valor para inclusión en destinos turísticos. 
Imagen 1. TIC para inclusión en la cadena de valor turística

\begin{tabular}{|c|c|c|c|c|c|}
\hline 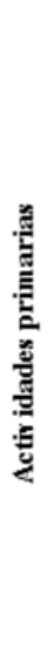 & $\begin{array}{l}\text { Creación de } \\
\text { productos. En } \\
\text { las rutasy } \\
\text { circuitos } \\
\text { turisticos hacer } \\
\text { uso de GPS para } \\
\text { personascon } \\
\text { discapacidad } \\
\text { cognitiva (DC) } \\
\text { y discapacidad } \\
\text { visual. Robótica } \\
\text { para } \\
\text { discapacidad } \\
\text { motora (DM). } \\
\text { Colores y LED } \\
\text { para rutas. }\end{array}$ & $\begin{array}{l}\text { Promoción. } \\
\text { Recursos } \\
\text { multim edia } \\
\text { com o } \\
\text { Im ágenes, } \\
\text { videos, } \\
\text { realidad } \\
\text { virtual. } \\
\text { Dispositivos } \\
\text { braille. }\end{array}$ & $\begin{array}{l}\text { Logística interna: } \\
\text { Los servicios de } \\
\text { acogida, transportey } \\
\text { seguridad. Con GPS, } \\
\text { PDA, celulares con } \\
\text { software } \\
\text { instruccional, para } \\
\text { DC y DV. Sistem as } \\
\text { de reconocimiento y } \\
\text { decodificación de } \\
\text { voz para } \\
\text { discapacida dauditiva } \\
\text { DA y del habla DH } \\
\text { para form alida des de } \\
\text { entra da y salida. } \\
\text { Dispositivos braille. }\end{array}$ & $\begin{array}{l}\text { Servicios del destino: } \\
\text { Alojamiento, ga stronomia, tours, } \\
\text { itinerarios, recorrido, activida des } \\
\text { de recreación, alquiles de } \\
\text { vehiculos e inform ación turistica. } \\
\text { Para llegar a lugares, GPS PDA y } \\
\text { software instruccional, DC y DV. } \\
\text { Tecnologias de a sistencia m édica } \\
\text { en alojam iento, y recorridos y } \\
\text { activida des de recreación. } \\
\text { Robótica y dom ótica para } \\
\text { a sistencia en hoteles para DM, } \\
\text { DV, DC. Sistem as OCR para DA } \\
\text { y DH para com unicación de } \\
\text { deseos y necesida des. Dispositivos } \\
\text { braille. Colores y LED para rutas } \\
\text { y lugares. }\end{array}$ & $\begin{array}{l}\text { Servicios } \\
\text { posv enta: } \\
\text { Gestión de } \\
\text { inform ación, } \\
\text { seguimiento del } \\
\text { cliente, m ediante } \\
\text { Dispositivos } \\
\text { braille, } \\
\text { reconocimiento } \\
\text { y decodificación } \\
\text { de voz, recursos } \\
\text { multim edia y } \\
\text { diversos ga dgets } \\
\text { para a sistir el } \\
\text { uso del } \\
\text { com puta dor. }\end{array}$ \\
\hline & \multicolumn{5}{|c|}{$\begin{array}{l}\text { Planifica ción del destino e infra estructura: En transporte y señalización GPS, PDA, celulares. Colores y led para } \\
\text { infra estructura turistica y señalización. }\end{array}$} \\
\hline 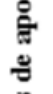 & \multicolumn{5}{|c|}{$\begin{array}{l}\text { Gestión del Recurso Hum ano. La sensibilización y actitud positiva hacia el turista, requiere de capacitación continua } \\
\text { en servicio al cliente y desarrollo del recurso hum ano. }\end{array}$} \\
\hline בֶ. & \multicolumn{5}{|c|}{$\begin{array}{l}\text { Desarrollo de recursos y productos m ejora am biental, aprovecham iento de nuevosm erca dosy segm entosy sistem as } \\
\text { de calidad. Las TIC facilitan el acceso a todoslos segm entosy aúnm ás al segm ento de persona scon algún tipo de }\end{array}$} \\
\hline & \multicolumn{5}{|c|}{$\begin{array}{l}\text { Tecnología y sistem as de informa ción tecnologiasy sistem as de inform ación com o conex ión a internet y redes } \\
\text { telefónicas, investigación de m erca dos, sistem as de reservas inform atiza dos }\end{array}$} \\
\hline
\end{tabular}

Fuente: Adaptado de Jonker (2004) citado en Reguera \& López (2014).

Las TIC pueden realizar aportes a las actividades centrales del sector, en la creación de productos turísticos que involucran las rutas y circuitos que el turista visita, el uso de GPS y artefactos que informan la ubicación y rutas son adecuados para personas con discapacidad cognitiva y visual, también los desarrollos robóticos permiten el desplazamiento y autonomía. En cuanto a la promoción, las TIC han sido utilizadas como vehículos para el marketing, los recursos multimedia también son útiles para la inclusión. En logística interna se promueve el transporte y seguridad con las TIC, también con GPS y localizadores acompañados de software que imparte instrucciones, los sistemas de reconocimiento y decodificación de voz son de gran ayuda para personas con dificultades auditivas y de lenguaje. Los servicios en el destino además de beneficiarse de la georreferenciación y herramientas como celulares y tablets pueden implementar sistemas de led para indicar ubicaciones de lugares de interés y prevenir riesgos; en servicio posventa las TIC ayudan en la comunicación con el consumidor.

\section{Conclusiones}

El segmento de turismo para personas con discapacidad está en crecimiento, debido al envejecimiento progresivo de la población y a la aparición de diver- 
sas enfermedades en la población mundial a edades cada vez más tempranas. Adicionalmente personas con discapacidad permanente han mostrado mayor interés en participar del turismo (Suriá \& Escalona, 2004), es por eso que expertos académicos y profesionales del turismo, afirman que el turismo accesible es un nicho que está en crecimiento y presenta importantes oportunidades (Wu \& Cheng, 2008), además de proveer una oportunidad económica, puede ser fuente de formación y trabajo para personas con discapacidad (Domínguez et al., 2015).

Los turistas con discapacidad constituyen un segmento de mercado significativo que no puede ser ignorado, igual que otros segmentos tienen necesidades especiales (Menzel \& Weldig, 2011). Una de ellas es la necesidad de ocio y requieren de ambientes adecuados (Domínguez et al., 2015). Adicionalmente las personas con discapacidad permanecen más en el lugar turístico y normalmente viajan con acompañantes (Pühretmair, 2004) quienes también consumen productos y servicios turísticos.

A medida que la tecnología de asistencia se ha desarrollado también lo ha hecho el mercado de tecnología de asistencia para discapacidad, las TI permiten el soporte a diferentes niveles de discapacidad según las necesidades del usuario (Bartfai \& Boman, 2011). La accesibilidad es esencial en el turismo responsable y sostenible, además de proteger los derechos humanos constituye una oportunidad de negocio.

La investigación sobre TIC para todos requiere mayor desarrollo (Koutkias, Kaklanis, \& Votis, 2016) y sobre todo incentivos para la inversión en TIC para la inclusión. Las tecnologías de asistencia para discapacidad normalmente están disponibles para países Europeos como Alemania, Reino Unido o Estados Unidos, son costosas y aún más en países con bajos ingresos, están disponibles en idioma inglés, circunstancias que generan un círculo vicioso que refuerza la desventaja para las personas con discapacidad especialmente en naciones en desarrollo (Hersh \& Mouroutsou, 2015), así aunque las tecnologías existan pueden se prohibitivas para población con bajos ingresos y de bajos niveles educativos, parece que la pobreza y la desigualdad son otros generadores de discapacidad.

\section{Referencias}

Abril, R. (2003). Libro blanco. Plan para la accesibilidad. Madrid: Ministerio de Trabajo y Asuntos Sciailes de España. Retrieved from http://ddd.uab.cat/record/45028

AENOR. (2007). Accesibilidad universal. Asociación española de Normalización y certificación. Retrieved from http:// www10.ujaen.es/sites/default/files/users/spe/SGAU-UJA/ UNE_170001-1=2007.pdf

Altinay, Z., Saner, T., Bahçelerli, N. \& Altinay, F. (2016). The Role of Social Media Tools : Accessible Tourism for Disabled Citizens. Educaional Technology and Society, 19(1), 89-99. Retrieved from http://www.jstor.org/stable/jeductechsoci.1 9.1.89?seq=1\#page_scan_tab_contents

Arboleda, C., Garcia, E., Posada, A. \& Torres, R. (2009). Diseño y construcción De un prototipo De interfaz cerebro-computaDor para facilitar la comunicación De personas con DiscapaciDaD motora. Revista EIA, 1, 105-115. Retrieved from http:// repository.eia.edu.co/bitstream/11190/209/1/REI00103.pdf

Bartfai, A. \& Boman, I.-L. (2011). Policies concerning assistive technology and home modification services for people with physical and cognitive disabilities in Sweden. NeuroRehabilitation, 28, 303-308. http://doi.org/10.3233/NRE-2011-0658

Benda, P., Havlícek, Z., Lohr, V. \& Havránek, M. (2011). ICT helps to overcome disabilities. Agris On-Line Papers in Economics and Informatics, 3(4), 63-69. Retrieved from http://online.agris.cz/

Bizjak, B., Knezeevic, M. \& Cvetreznik, S. (2011). Attitude change towards guests with disabilities. Reflections From Tourism Students. Annals of Tourism Research, 38(3), 842-857. http://doi.org/10.1016/j.annals.2010.11.017

Brida, J., Monterubbianesi, P. \& Zapata, S. (2011). Impactos del turismo sobre el crecimiento económico y el desarrollo. El caso de los principales destinos. Pasos, 9, 291-303. Retrieved from http://www.redalyc.org/articulo.oa?id=88117284006

Buhalis, D. \& Law, R. (2008). Progress in information technology and tourism management: 20 years on and 10 years after the Internet-The state of eTourism research. Tourism Management, 29(4), 609-623. http://doi.org/10.1016/j. tourman.2008.01.005

Busby, G. (2006). Historic, Contemporary, and Future Effects of Information and Communication Technologies ( ICT ) on People with Impairments. In Perspectives and Policies on ICT in Society (p. 263). Retrieved from http://www.springer. $\mathrm{com} / \mathrm{gb} / \mathrm{book} / 9780387255873$

Calvo, A., Navarro, A. \& Periañez, R. (2015). Tourism for all and performance: An analysis of accessibility management in hotels. In Achieving Competitive Advantage through Quality Management (p. 312). Springer International Publishing. http://doi.org/10.1007/978-3-319-17251-4

Castells, M. (2001). La era de la información: Economía, sociedad y cultura (3rd ed.). Madrid: Siglo 21 Editores.

Caulfield, B., Conway, T. \& Micera, S. (2012). European study of research and development in mobility technology for persons with disabilities. Journal of NeuroEngineering and Rehabilitation, 9, 23. http://doi.org/10.1186/1743-0003-9-23 
Cobo, E., Sandoval, C. \& Alvarado, Y. (2012). Magnitud de la discapacidad en Boyacá, Colombia. Revista de Salud Pública, 14(5), 776-778. Retrieved from http://www.redalyc.org/ articulo.oa?id=42229127005

Colak, H. E. \& Aydinoglu, A. C. (2006). Determining Regional Tourism Development Strategies of East Black Sea Region of Turkey by GIS. In XXIII FIG Congress (pp. 1-9). munich, Germany. Retrieved from https://www.fig.net/resources/ proceedings/fig_proceedings/fig2006/papers/ts72/ts72_03_ colak_aydinoglu_0545.pdf

Comunello, F., Mulargia, S., Belotti, F. \& Fernández-Ardèvol, M. (2015). Evaluating All-Inclusive ICT with Developers, end users and stakeholders. Human Aspects of IT for the Aged Population., 9193, 439-450. http://doi.org/10.1007/9783-319-20892-3

Continuo, A. (2013). El dispositivo de discapacidad. Tesis Psicológica, 8(1), 174-183. Retrieved from http://www.redalyc. org/articulo.oa?id=139029198013

Cook, A. (2008). Using the web and ICT to enable persons with disabilities. Communications in Computer and Information Science, 25, 3-18. http://doi.org/10.1007/978-3-54092219-3_1

Coppola, S., Sakornsatian, S., Thongkuay, S. \& Trevittaya, P. (2012). Innovative practice in accessible and inclusive tourism. World Federation of Occupational Therapists Bulletin, 66, 43-46. http://doi.org/10.1179/otb.2012.66.1.016

Dekelver, J., Kultsova, M., Shabalina, O., Borblik, J., Pidoprigora, A. \& Ramanenko, R. (2015). Design of movil aplication for people with intellectual disabilities. Communications in Computer and Information Science, 535, 637-654. http:// doi.org/10.1007/978-3-319-23766-4

Delvigne, M., Santos, A., Tardot, A., Devilleger, M., Fortin, A., Maitre, T., ... Dussartre, A. (2011). Using code of colors through ICT and home automation technologies in the housing environment context for persons with loss of autonomy. Lecture Notes in Computer Science, 6719 LNCS(6719), 200-204. http://doi.org/10.1007/978-3-642-21535-3_26

Domínguez, T., Darcy, S. \& Alén, E. (2015). Competing for the disability tourism market - A comparative exploration of the factors of accessible tourism competitiveness in Spain and Australia. Tourism Management, 47, 261-272. http://doi. org/10.1016/j.tourman.2014.10.008

Domínguez, T., Fraiz, A. \& Alén, M. (2015). Discapacidad y alojamientos turísticos en España Trinidad Domínguez Vila. Pasos. Revista de Turismo Y Patrimonio Cultural, 13(4), 771-787. http://doi.org/10.1108/JTF-08-2015-0043

Drucker, P. (1990). Llega una nueva organización a la empresa. In Gestiónd el Conocimiento (pp. 1-21). Harvard Business Review.

Egea, C. \& Sarabia, A. (2001). Clasificaciones de la OMS sobre discapacidad. Artículos Y Notas. Retrieved from http:// usuarios.discapnet.es/disweb2000/art/ClasificacionesOMSDiscapacidad.pdf

García, M. (2015). Discapacidad. Especial referencia a la educación. RIPS, 14(1), 193-208. Retrieved from http://www.redalyc. org/articulo.oa?id=38041418009
García, A. \& Rodríguez, C. (2000). Nuevas tecnologías y personas con discapacidad New technologies and people with disability. Psycholsocial Intervention, 9(3), 283-296. Retrieved from http://www.redalyc.org/articulo.oa?id=179818254002

Göksu, 囚. \& Atici, B. (2013). Need for Mobile Learning: Technologies and Opportunities. Procedia - Social and Behavioral Sciences, 103, 685-694. http://doi.org/10.1016/j.sbspro.2013.10.388

Gómez, L., Avella, A. \& Moralez, L. (2015). Observatorio de Discapacidad de Colombia. Revista Facultad Nacional de Salud Pública, 33(2), 277-285. http://doi.org/10.17533/ udea.rfnsp.v33n2a14

Gutierrez, P. \& Martorell, A. (2011). Las personas con discapacidad intelectual ante las TIC. Comunicar, 18(36), 173-180. http://doi.org/10.3916/C36-2011-03-09

Hall, T., Cohen, N., Vue, G. \& Ganley, P. (2015). Addressing Learning Disabilities With UDL and Technology: Strategic Reader. Learning Disability Quarterly, 38, 72-83. http:// doi.org/10.1177/0731948714544375

Hersh, M. A. \& Mouroutsou, S. (2015). Learning Technology and Disability: Overcoming Barriers to Inclusion: Evidence from a Multi-Country Study. IFAC-PapersOnLine, 48(24), 83-88. http://doi.org/http://dx.doi.org/10.1016/j.ifacol.2015.12.061

Ivanović, A. (2015). Business opportunity and social responsibility: Growing importance of accessible e-tourism for senior tourists and persons with disabilities. In New business oportunity in the growing E-Tourism industry. (pp. $303-336)$. IGI Global. http://doi.org/10.4018/978-1-4666-8577-2.ch016

Jimenéz, P. \& Aquilino, G. (2012). Propuesta de un modelo de competitividad de destinos turísticos. Estudios Y Perspectivas En Turismo, 21, 977-995. Retrieved from http://www.scielo. org.ar/pdf/eypt/v21n4/v21n4a10.pdf

Jurado, M. (2014). El turismo accesible en Andalucía y Portugal. Cuadernos de Turismo, (33), 121-150. http://doi. org/10.12795/rea.2014.i31.01

Kaplinsky, R. \& Morris, M. (2000). A hand book for value chain research. Institute for Development Studies: Brighton, UK, (September), 4-7. Retrieved from https://www.ids.ac.uk/ids/ global/pdfs/VchNov01.pdf

Kascak, L., Lee, S., Liu, E. \& Sanford, J. (2015). The expansion of a Scheme about accesibility in tourism at the cultural sector. Springer International Publishing Switzerland. Retrieved from http://www.scopus.com/inward/record. url?eid=2-s2.0-84947232122\&partnerID=tZOtx3y1

Koutkias, V., Kaklanis, N. \& Votis, K. (2016). An integrated semantic framework supporting universal accessibility to ICT. Universal Access in the Information Society, 15, 49-62. http://doi.org/10.1007/s10209-014-0372-1

Lancioni, G. E., Singh, N. N., O'Reilly, M. F., Sigafoos, J., Boccasini, A., Alberti, G. \& Lang, R. (2014). People with Multiple Disabilities Use Basic Reminding Technology to Engage in Daily Activities at the Appropriate Times. Journal of Developmental and Physical Disabilities, 26, 347-355. http://doi.org/10.1007/s10882-014-9373-5 
Lancioni, G. E., Singh, N., O'Reilly, M., Sigafoos, J., Oliva, D., Alberti, G. \& Buono, S. (2014). Persons with Multiple Disabilities Choose Among Environmental Stimuli Using a Smile Response and a Technology-Aided Program. Journal of Developmental and Physical Disabilities, 26, 183-191. http://doi.org/10.1007/s10882-013-9353-1

Leeuwen, E. \& Nijkamp, P. (2011). Operational advances in tourism Research Memorandum 2011-19. Ansterdam. Retrieved from http://dspace.ubvu.vu.nl/bitstream/handle/1871/19532/rm 2011-19.pdf?sequence=2

Li-Tsang, C., Chan, C., Lam, C., Hui-Chan, C. \& Yeung, S. (2004). Evaluations of an information and communication technology (ICT) training programme for persons with intellectual disabilities. Lecture Notes in Computer Science, 3118, 1032-1038. http://doi.org/10.1007/978-3-540-27817-7_152

Li-Tsang, C., Lee, M., Yeung, S., Siu, A. \& Lam, C. S. (2007). A 6-month follow-up of the effects of an information and communication technology (ICT) training programme on people with intellectual disabilities. Research in Developmental Disabilities, 28, 559-566. http://doi.org/10.1016/j.ridd.2006.06.007

Luque, D. \& Luque, M. (2012). Aspectos psicoeducativos en las relaciones de las TIC y la discapacidad intelectual. Revista Internacional de Psicología Y Educación, 14(1), 27-48. Retrieved from http://www.redalyc.org/articulo.oa?id=80224034003

Mclane, K. (2007). Student Progress Monitoring. Special Education. Washington. DC: National Center on Student Progress Monitoring. Retrieved from http://www.studentprogress.org/ doc/CurriculumBasedMeasurement.pdf

Menzel, N. \& Weldig, A. (2011). The Long Tail of Tourism. In Inclusive tourism (pp. 201-211). http://doi.org/10.1007/9783-8349-6231-7

Ministerio de Comercio Industria y Turismo. (2011). Plan Sectorial de Turismo 2011-2014 "Turismo: factor de prosperidad para Colombia." Bogotá.

Monterrubio, C. (2009). Comunidad receptora: Elemento esencial en la gestión turística. Gestión Turistica, 11, 101-111. Retrieved from http://www.redalyc.org/articulo.oa?id=223314808005

Moreno, M., Rodríguez, M., Gutierrez, M., Ramírez, L. \& Barrera, O. (2006). Aquichan. Aquichan, 6(1), 78-91. Retrieved from http://www.redalyc.org/articulo.oa?id=74160109

Navas, P., Verdugo, M. A. \& Gómez, L. E. (2008). Diagnóstico y clasificación en discapacidad intelectual Diagnosis and classification on intellectual. Intervención Psicosocial, 17(2), 143-152. Retrieved from http://www.redalyc.org/articulo. oa?id=179814018004

Nicholl, H., Doyle, C. \& College, T. (2013). Identifying the types of technology that are used by children with intellectual disabilities and associated complex needs living at home in Ireland. British Journal of Learning Disabilities, 41, 229-236. http://doi. org/10.1111/bld. 12045

Nicolae, J. C. \& Sabina, D. B. M. (2012). The ICT Implication on CSR in the Tourism of Emerging Markets. Procedia Economics and Finance, 3(12), 702-709. http://doi.org/10.1016/ S2212-5671(12)00217-1

Niemeijer, A., Frederiks, B., Depla, M., Eefsting, J. \& Hertogh, C. (2013). The place of surveillance technology in residential care for people with intellectual disabilities: Is there an ideal model of application. Journal of Intellectual Disability Research, 57(march), 201-215. http://doi.org/10.1111/j.13652788.2011.01526.x

Norton, D. \& Kaplan, R. (2000). El cuadro de mando integral. Edisiones Gestión.

Obi, T., Ishmatova, D. \& Iwasaki, N. (2013). Promoting ICT innovations for the ageing population in Japan. International Journal of Medical Informatics, 82(4), e47-e62. http://doi. org/10.1016/j.jimedinf.2012.05.004

Oliver, A., Sancho, P. \& Galiana, L. (2012). Calidad de la empleabilidad en universitarios con discapacidad. Revista Iberoamericana de Psicologia Y Salud., 3(2), 109-123. Retrieved from http://www.redalyc.org/articulo.oa?id=245124456002

OMS. (2001). Clasificación Internacional del Funcionamiento, de la Discapacidad y de la Salud. (OMS, Ed.), Revista Española de Salud Pública (Vol. 76). http://doi.org/10.1097/01. pep.0000245823.21888.71

OMS. (2011). Informe mundial sobre la discapacidad. Educación. Organización Mundial de la Salud. Retrieved from http://who. int/disabilities/world_report/2011/summary_es.pdf

OMT. (2014). Recomendaciones de la OMT por un turismo accesible para todos. Madrid: OMT. Retrieved from http:// ethics.unwto.org/es/publication/recomendaciones-de-la-omtpor-un-turismo-accesible-para-todos

OMT. (2015). Recomendaciones de la OMT sobre accesibilidad de la información turística. OMT.

ONU. (2002). Departamento de asuntos Económicos y sociales de las naciones Unidas División de Población, World Population Ageing: 1950-2050. Nueva York. Retrieved from http://www. un.org/esa/population/publications/worldageing19502050/ pdf/001world.pdf

ONU. (2008). Convención sobre los Derechos de las Personas con Discapacidad. Retrieved from http://www.un.org/esa/ socdev/enable/documents/tccconvs.pdf $\backslash$ nhttp://www.acnur. org/t3/fileadmin/scripts/doc.php?file=biblioteca/pdf/6401

Ospina, M. (2010). Discapacidad y sociedad democrática. Revista Derecho Del Estado, 24, 143-164. Retrieved from http:// www.redalyc.org/articulo.oa?id $=337630234007$

Ozols, M. (2007). Actividad física y discapacidad. MH Salud, 4(2), 1-5. Retrieved from http://www.redalyc.org/articulo. oa?id=237017534001

Packer, T. L., McKercher, B. \& Yau, M. K. (2007). Understanding the complex interplay between tourism, disability and environmental contexts. Disability and Rehabilitation, 29(February), 281-292. http://doi.org/10.1080/09638280600756331

Padilla, A. (2010). Discapacidad : contexto, concepto y modelos * Disability : context, concept and models. International Law, (16), 381-414. Retrieved from http://www.redalyc.org/ articulo.oa?id=82420041012

Pagán, R. (2012). Time allocation in tourism for people with disabilities. Annals of Tourism Research, 39(3), 1514-1537. http://doi.org/10.1016/j.annals.2012.04.005

Parra, C. (2013). Estructura institucional de la discapacidad en el Estado colombiano. Civilizar. Ciencias Sociales Y Humanas, 
13(24), 79-102. Retrieved from http://www.redalyc.org/ pdf/1002/100228407007.pdf

Porter, M. (1991). La ventaja competitiva de las naciones. Ed Vergara. Argentina (Vergara). Buenos Aires, Argentina.

Porter, M. E. (2001). Strategy and the Internet. Harvard Business Review, 1-20. Retrieved from http://web.uncg.edu/bae/ lsiyer/ec_common/articles/strategy_and_internet_porter.pdf

Puehretmair, F., \& Woess, W. (2008). A flexible concept to establish accessibility information in tourism web-pages. Computers Helping People with Special Needs, Proceedings, 5105, 981-988. Retrieved from <Go to ISI>:// WOS:000258398900147

Pühretmair, F. (2004). It's time to make eTourism accessible. Computers helping people with special needs. Retrieved from http:// link.springer.com/chapter/10.1007/978-3-540-27817-7_41

Quintero, P., Bernal, C. \& López, H. (2005). La competitividad turística de Cartagena de Indias. In La competitividad turística de Cartagena de Indias: análisis del destino y posicionamiento en el mercado (p. 121). Cámara de Comercio de Cartagena. Retrieved from file:///C:/Users/Diana/Downloads/2009062513_INV_NO4LAC-1.PDF

Ratliffe, K. T., Rao, K., Skouge, J. R. \& Peter, J. (2012). Navigating the currents of change: technology, inclusion, and access for people with disabilities in the Pacific. Information Technology for Development, 18(3), 209-225. http://doi.org/10.108 $0 / 02681102.2011 .643207$

Reguera, A. \& López, A. (2014). Urueña, Villa del Libro. Aproximación a la imagen de un destino. Universodad de Valladolid. Retrieved from https://uvadoc.uva.es/bitstream/10324/5990/1/TFG-N.98.pdf

Ripat, J. D. \& Woodgate, R. L. (2011). Locating assistive technology within an emancipatory disability research framework. Technology and Disability, 23, 87-92. http://doi.org/10.3233/ TAD-2011-0315

Røssvoll, T. H. \& Fuglerud, K. S. (2013). Best Practice for Efficient Development of Inclusive ICT. Berlin: Springer-Verlag. Retrieved from link.springer.com/chapter/10.1007/978-3-6

Rumetshofer, H. \& Wolfram, W. (2004). Tourism information systems promoting barrier-free tourism for people with disabilities. Computers Helping People with Special Needs, 627. http://doi.org/10.1007/978-3-540-27817-7

Sanmargaraja, S. \& Wee, S. T. (2015). The need of accessible accommodation in Malaysian tourism sector: Case study in Endau-Rompin and Ledang Hills National Parks. International Business Management, 9(1), 139-144. http://doi. org/10.3923/ibm.2015.139.144

Schreuer, N., Keter, A. \& Sachs, D. (2007). Accessibility to Information and Comunications technology for the Social Participation of Youths with Disabilities: A two-way Street. Behavioral Sciences \& the Law, 28, 211-223. http://doi. org/10.1002/bsl

Scott, M., Spyridonis, F. \& Ghinea, G. (2015). Designing for designers: Towards the development of accessible ICT products and services using the VERITAS framework. Computer Standards \& Interfaces, 42, 113-124. http://doi.org/10.1016/j. csi.2015.05.004
Seng, B. (2015). ICT for sutainable development of the tourism industry in Cambodia. Springer International Publishing Switzerland (Vol. 8944).

Simsek, Ö., Altun, E. \& Ates, A. (2010). Developing ICT skills of visually impaired learners. Procedia - Social and Behavioral Sciences, 2, 4655-4661. http://doi.org/10.1016/j. sbspro.2010.03.745

Stock, S. E., Davies, D. K., Wehmeyer, M. L. \& Lachapelle, Y. (2011). Emerging new practices in technology to support independent community access for people with intellectual and cognitive disabilities. NeuroRehabilitation, 28, 261-269. http://doi.org/10.3233/NRE-2011-0654

Suriá, R., \& Escalona, J. (2004). Integración, Turismo y discapacidad : ¿son accesibles los hoteles para als personas con discapacidad física? Revista de Turismo Y Patrimonio Vultural, 12(1), 209-2018. Retrieved from http://www.redalyc.org/ articulo.oa?id=88129335016

Toboso, M. (2011). Rethinking disability in Amartya Sen's approach: ICT and equality of opportunity. Ethics and Information Technology, 13(Stiker 1999), 107-118. http://doi. org/10.1007/s10676-010-9254-2

Toffler, A. (1990). El cambio de poder. Plaza \& Jones Editores S.A.

Torii, I., Ohtani, K., Niwa, T. \& Ishii, N. (2013). Development of Support Applications for Elderly and Handicapped People with ICT Infrastructure. In Communications in Computer and Information Science (pp. 266-270). Retrieved from http:// link.springer.com/chapter/10.1007/978-3-642-39473-7_54

Torres, P. \& Merrero, M. (2014). Algunas Consideraciones Sobre La Medición de La Competitividad De Destinos Turísticos. Retos Turísticos, 2(2). Retrieved from http://retos.mes.edu. $\mathrm{cu} /$ index.php/retojs/article/view/60

Ulbricht, V. R., Vanzin, T., Amaral, M., Vilarouco, V., De Quevedo, S. R. P., Moretto, L. A. M. \& Flores, A. R. B. (2012). A tool to facilitate including accessible content in moodle to the person with visual impairment. Procedia Computer Science, 14(Dsai), 138-147. http://doi.org/10.1016/j.procs.2012.10.016

UNWTO. (2014). Manual sobre Turismo Accesible para Todos: Principios, herramientas y buenas prácticas. Retrieved from http://www.accessibletourism.org/resources/manualturismoaccemoduloipruebadia14final1revisadov2.pdf

Ventura, V. (2011). El turismo, su cadena productiva y el desarrollo incluyente en América Latina : los casos de Brasil y México. Working Paper, 138, 2-78.

Weber, H. \& Zink, K. (2014). Boon and Bane of ICT Acceleration for Vulnerable Populations. In The impact of ICT on quality of working life (pp. 177-190). Germany: Institute of Technology and Work University of Kaiserslautern. http:// doi.org/10.1007/978-94-017-8854-0

Wise, P. H. (2012). Emerging technologies and their impact on disability. Future of Children, 22(1), 169-191. http://doi. org/10.1177/135676679400100110

WTO. (2016). Annual Report 2015. Annual Report 2015.

Wu, Y. C. J. \& Cheng, M. J. (2008). Accessible tourism for the disabled: Long tail theory. Lecture Notes in Computer Science (Including Subseries Lecture Notes in Artificial Intelligence 
and Lecture Notes in Bioinformatics), 5288 LNAI, 565-572. http://doi.org/10.1007/978-3-540-87781-3_61

Zhang, Y., Gan, Y., Cham, H., Wang, M.-T., Willett, J. B., Eccles, J. S., ... Appleton, J. J. (2012). School Engagement
Trajectories and Their Differential Predictive Relations to Dropout. Journal of Adolescence, 74(3), 274-283. http:// doi.org/10.1002/pits 